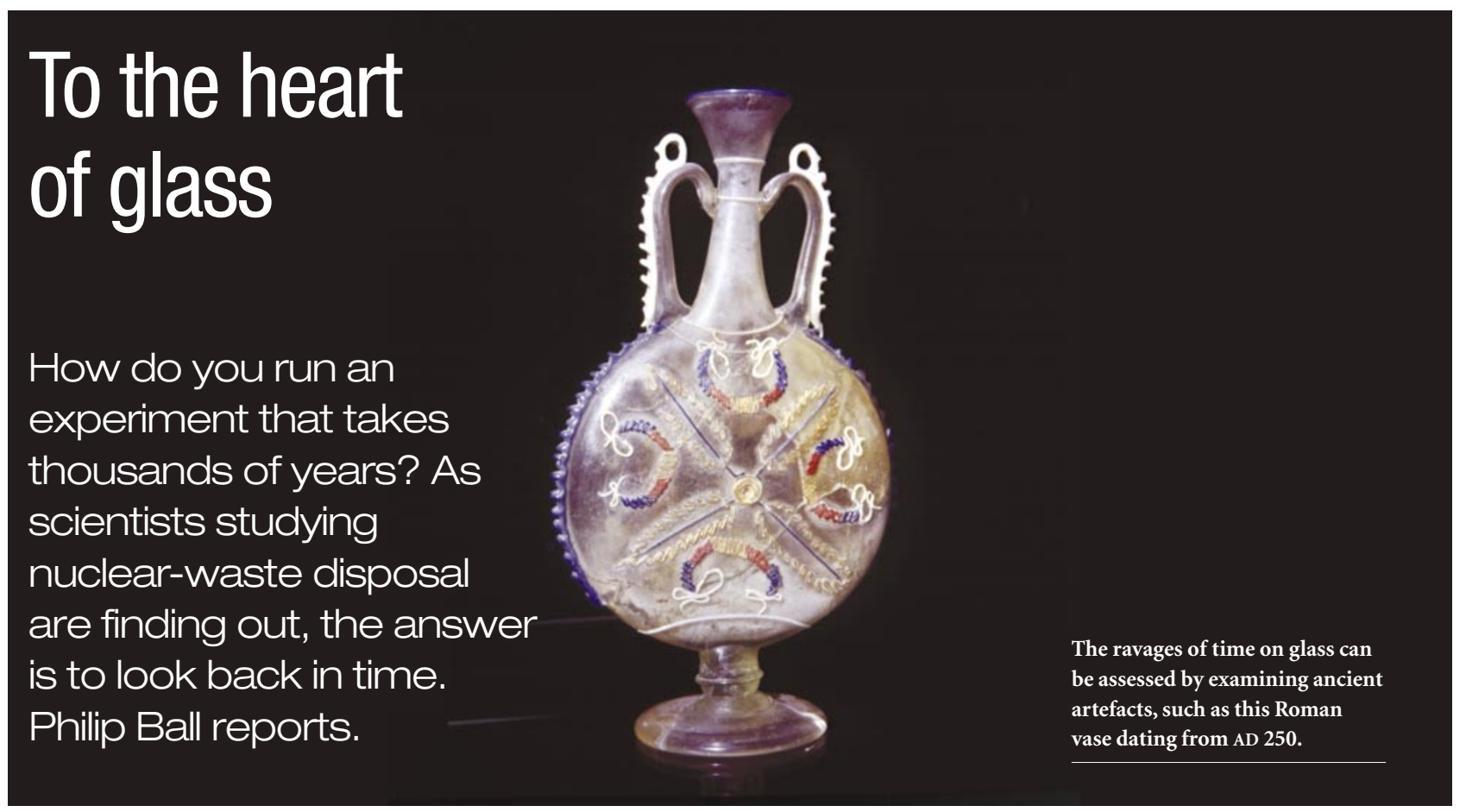

f you feel that your experiments can take for ever, spare a thought for the scientists studying the disposal of nuclear waste. The half-lives of some radioactive wastes stretch to hundreds of thousands of years. How can the materials used to contain these wastes ever be properly tested?

The solution, or at least part of it, is to collaborate with archaeologists. One of the best disposal options is to trap the waste in glass and bury it. So when the civilizations of the Middle East first learnt how to make glass at least 4,500 years ago, they unwittingly launched an experiment on the long-term stability of the favoured material for storing nuclear waste. Archaeologists have since excavated samples of these glasses, and their findings could help materials scientists improve nuclear-waste disposal.

The two communities have actually been courting each other sporadically for at least two decades, but nuclear waste is now an increasingly pressing problem. In the United States alone, 400 million litres of high-leve waste - spent fuel from nuclear power plants and the military reactors used to make weapons-grade plutonium need to be stored. A proposed repository inside Yucca Mountain in Nevada has attracted much controversy (see Nature $412,850-852 ; 2001$ ), although it is expected to open early next decade. With the need to test potential storage materials high on the agenda of nuclear-waste researchers, the relationship with archaeologists got off to a fresh start in Boston last December, at the annual meeting of the US Materials Research Society.

Glass is already an established part of the waste-disposal process. Since 1996, a plant at the Savannah River Site, a former nuclearweapons production facility in South Carolina, has been mixing high-level waste into molten glass and casting it into cylinders about a cubic metre in volume. AtYucca, these would be placed in canisters made of a corrosionresistant nickel alloy. But water is likely to seep into the underground chambers holding the waste. No one knows for sure if the alloy will hold out over thousands of years, so materials scientists are interested in how water will affect the encased glass over long periods of time.

\section{Waste cocktail}

Normal glass consists mainly of a disorderly network of silicon and oxygen atoms. Typically incorporated into this network are small amounts of metals such as sodium and calcium, which are introduced to make it easier to process

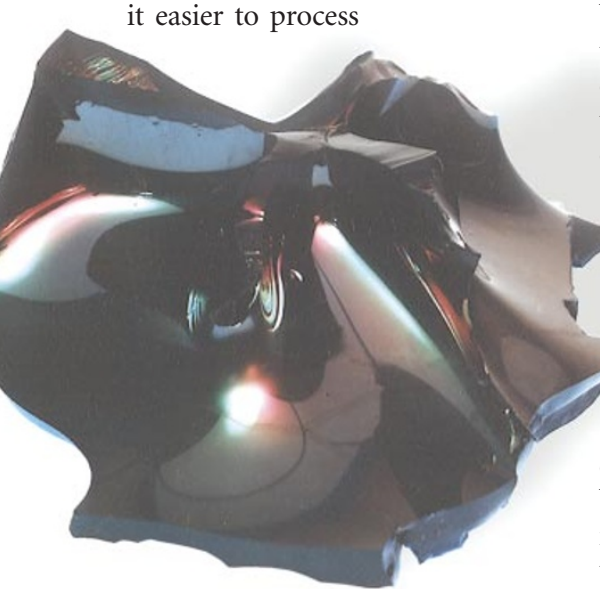

Glass is stable, but is it sufficiently robust to store nuclear waste for hundreds of thousands of years? the glass. Larger metallic elements, including heavy radioactive elements such as caesium and neptunium that are found in nuclear waste, can be caught and held within this silicate network. Stable and robust, glass seems to be an ideal option for storing waste.

But over the thousands of years that nuclear waste remains active, glass can undergo significant changes. For relatively short periods of time, a few years say, water barely perturbs silicate glass. But hydrogen ions in water will eventually swap places with the sodium and calcium in the glass, slowly disrupting the network and allowing some of the radioactive elements to escape.

What's more, silicate glass can transform into a crystalline form over hundreds of years, squeezing the radioactive atoms out of the crystal lattice in the process. The glass will also be exposed to high levels of radiation and, for the first few decades, heat from the radioactive elements will create defects in the glass structure that can initiate further damage. The key question is not if nuclear waste will eventually leak out, but when and how fast.

Vital clues could come from studies of ancient glass. The earliest-known artificial glass comes from Mesopotamia, now part of

Syria and Iraq, and dates from 2500 BC.

The ancient Egyptians also developed

considerable expertise in glassmaking, although it remained a luxury item throughout the Middle Ages. These glasses were made by fusing sand with substances that contained metals from groups I and II of the periodic table, such as sodium, found in wood ash.

This is fortunate, as several of the recipes being studied for nuclear-waste glasses also contain high amounts of such metals. Some of 
